\title{
Introduction: Reading Matter
}

\section{Citation}

Price, Leah. 2006. Introduction: Reading matter. PMLA 121(1): 9-16.

\section{Published Version}

http://dx.doi.org/10.1632/003081206X96087

\section{Permanent link}

http://nrs.harvard.edu/urn-3:HUL.InstRepos:3347577

\section{Terms of Use}

This article was downloaded from Harvard University's DASH repository, and is made available under the terms and conditions applicable to Open Access Policy Articles, as set forth at http:// nrs.harvard.edu/urn-3:HUL.InstRepos:dash.current.terms-of-use\#OAP

\section{Share Your Story}

The Harvard community has made this article openly available.

Please share how this access benefits you. Submit a story.

\section{Accessibility}


Leah Price

Introduction: Reading Matter

Published in PMLA 121, no. 1 (January 2006)

Early in Thomas Hardy's novel Desperate Remedies, the narrator announces his intention "to turn now to the more material media through which this story moves." Today, literary criticism is making that turn. There's nothing new, of course, about attention to the material media of texts (brass, stone, marble or gilded monuments); nor is an interest in the movement of stories - their circulation, transmission, and reception - a recent invention. Bibliography, paleography, and editing have been central to scholarship (and not just literary scholarship) since at least the fifteenth century. In the twentieth, the book has stood at the center of the analytical bibliography developed in the anglophone world, the literacy statistics crunched by the Annalistes, the biographies of authors and histories of publishing houses which provided later cultural theorists with their raw material, the social-science fictions crafted by Walter Ong and Marshall McLuhan. But only in the past few decades have those enterprises coalesced into a discipline that owns up to a raft of aliases: book history, print culture, media studies, textual scholarship. Its own material media include multi-volume national histories of the book (1982-86 in France, in process in the United States and elsewhere); a professional society with a prizewinning journal (Book History), a hyperactive

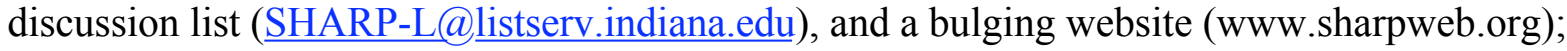
and a growing canon of textbooks, anthologies and degree programs. ${ }^{1}$

So far, so triumphalist. According to some media theorists, our own working conditions will inevitably revive interest in past bibliographic forms. In their account, the advent of the screen has made it harder to take the page for granted: the death of the book means the birth of its history. Seth Lerer's afterword to this issue identifies one of the fallacies undergirding that narrative: that the book is history. If anything, electronic technologies have lent new life to old bibliographic forms. Online inventory systems made possible the rise of retailers like Amazon.com in the same years when the spread of personal computers drove up paper consumption. Nor is a sensitivity to material media universal, at least among the readership of this journal. On the first day of English class, every freshman learns that "book" is a dirty word: what they're reading now needs to be called a "text." This is more than a euphemism, of course: one refers to a material object, the other to a sequence of words. But it's fair to say that the former continues to inspire many literary critics with either embarrassment or ennui. David Scott Kastan, himself an expert on early modern print culture, has even troped on our discipline's thirst for the "New" (as in Criticism and Historicism) to dub book history "The New Boredom."

In that context, our four-part title may sound like a shotgun marriage. "Idea" and "history": to the disciplines represented in the MLA, "book history" has come to stand for a materialist resistance to theory, to idealism, even to ideas. "Literature" and the "book": bibliographers's failure to account for the specificity of the literary is all the more striking given how often their raw materials are borrowed from a canon established by literature departments. In 1932, W.W. Greg declared that "Books are the material means by which literature is transmitted; therefore bibliography, the study of books, is essentially the science of the transmission of literary documents." Greg himself must have realized the weak link in the syllogism: elsewhere he defined 
bibliography as "the study of the material transmission of literary and other documents."

How "essential," in Greg's words, is literariness to the history of the book, or bibliographic form to an analysis of the literary? Meredith McGill has argued recently that "the shift of the object of study within literary criticism from texts to discourses has left open the question of ... how ... changes in the material conditions of textual production, distribution, and reception affect the relationship between literature and other discourses." McGill's disciplinary point could be rephrased in institutional terms: because successive waves of historicism and cultural studies have washed every genre of written discourse onto the shores of English departments, the path of least resistance for those of us trying to find a home for our field is to treat book history as a subset of literary criticism.

But what if it were the other way around? What if, instead of asking what book history can do for literary criticism, we asked what literary theory can do for book history? ${ }^{3}$ In that case, PMLA subscribers would need to recognize their own discipline as one small corner of what D.F. McKenzie described as the "sociology of texts," with "texts" taken

to include verbal, visual, oral, and numeric data, in the form of maps, prints, and music, of archives of recorded sound, of films, videos, and any computer-stored information, everything in fact from epigraphy to the latest forms of discography.

In other words, the kitchen sink. (McKenzie was speaking at the British Library, an institution struggling to store and catalogue the swelling number of non-bibliographic materials that come to it by legal deposit.) Whether or not you accept the expansionism that McKenzie uses to put a utopian face on information overload, it's beyond debate that those works which we group under the rubric of "literature" have never made up more than a fraction of printed matter. Simon Eliot has calculated that according to the 1907 Census of Production in Britain, "books were worth some 14 $\%$ of the total value of print production (and that included manuscript books and ledgers). The two areas of largest value were ... jobbing printing and periodical printing. The most common reading experience, by the mid-nineteenth century at latest, would most likely be the advertising poster, all the tickets, handbills and forms generated by an industrial society, and the daily or weekly paper."

The scant attention devoted to tickets and handbills may suggest that book historians' case studies have been imported wholesale from whatever cognate discipline happens to carry the greatest institutional weight - in this case, literary criticism. Inevitably, that borrowing skews the generalizations that we draw about reading. A decade ago, Allen Renear challenged literary critics to account for the more mundane protocols of "office automation, textual editing, text processing software"; a year earlier, Paul Duguid argued that the paratext would take on a rather different history if we recognized that "forms of standardization [such as] (indexing, alphabetisation, page numbers) were refined first in the counting house before appearing in print."

Lorraine Piroux's discussion of the Lettres d'une Peruvienne in this issue cuts across the divide that Duguid describes. It does so by contesting the fantasies about writing that motivated both Enlightenment and twentieth-century critics' attempts to distinguish Inca quipus (imagined as purely arithmetic or mnemonic in their function) from the Western book (imagined as a purely instrumental vehicle for ideas). Neatly inverting our title, Piroux's paper focuses on what might be called the history of literature and the idea of the book. Her interest lies less in writing practices themselves than in the challenge that literariness poses to theories of writing which render their 
own medium invisible. Graffigny replaces the Enlightenment ideal of linguistic and bibliographic transparency, Piroux argues, by a double interest in the materiality of the book and the opacity of the sign. Once books are placed in the hands of owners who recognize neither their language nor even their alphabet, illegibility throws their material attributes into relief. As with any purloined letter, we come to look at the book-object only once cultural difference prevents us from seeing through it. The less legible, the more visible - but also, in Piroux's analysis, the more literary. In Graffigny's novel, Piroux finds an allegory of the question that this issue tries to address: how to reconcile reading with seeing, and linguistic structures with bibliographic objects.

Right up to the end of the last century, the culture wars were often fought as if both sides assumed historicism to be the opposite of formalism - the latter disputed in turn between impractical theorists and practical critics who defined their object of study as "the words on the page." The problem was that the second half of the phrase rarely rose above the metaphorical; it remained for book history to upstage the text (a sequence of "words") by its tangible form (the "page"). When critics speak of "formalism," they usually mean verbal form; in contrast, book historians keep redrawing the boundary separating substance (the words themselves) from accidence (extrinsic features such as spelling, spacing, and typeface). Far from replacing hermeneutics by pedantry, book history insists that every aspect of a literary work bears interpretation - even, or especially, those that look most contingent.

For common readers no less than literary critics, the text has traditionally been the end, the book (at best) the means. Elaine Scarry has defined imaginative literature precisely by its power to drown out the significance that would otherwise be attached to its material form. Unlike music, sculpture, or painting, she points out, "verbal art, especially narrative, is almost bereft of any sensuous content. Its visual features ... consist of monotonous small black marks on a white page." In fact, Scarry argues, what little sensory response the book does provoke is "not only irrelevant but even antagonistic to the mental images that a poem or novel ... produce[s]." From a bibliographic perspective, however, the bifurcation which Scarry associates with verbal "art" appears to inhere not in literature, but in print. Carlo Ginzburg has argued that the first humanist printings of the classics set aside sensory data in the process of devaluing all those aspects of documents that vary from one copy to another. We tend to think of the esthetic as a sphere of heightened attention, but Ginzburg's and Scarry's otherwise dissimilar arguments recast it as a product of refusals to attend. Hunches about what counts as substance and what as accidence reflect a less conscious decision about what kinds of sense data to bracket. Those implicit rules about what to ignore intensify esthetic experience in the process of narrowing it.

If the book has been invisible (or intangible) to most twentieth-century literary critics, in other words, it isn't simply because we aren't trained to analyze material culture; it's also because a common-sense cartesianism teaches us to filter out the look, the feel, the smell of the printed page. Hence critics' discomfort with purely bibliographic units - the page-break as opposed to the linebreak, the volume as opposed to the chapter. We can ignore those markers when they coincide: the novel is now defined in part as a form that can fit into one volume, for example, and the sonnet has usually been sized to fit on a page. In "Breaking the Book Known as 'Q,', Coleman Hutchison asks what happens when it doesn't. Unlike nearly every other sonnet sequence from the period, the 1609 quarto of Shake-speares Sonnets run poems across page-breaks. That few readers have registered that fact reflects our impulse to grant meaning to some elements of the book and 
withhold it from others. Yet Hutchison finally parses the relation of bibliographic to linguistic codes (to borrow Jerome McGann's phrase) as symbiosis rather than competition. By juxtaposing the text's thematic contents with the book's material form, he reveals that sonnet 55's contrast between the durability of words and the disposability of writing surfaces comes at precisely the moment when a page-break forces the reader to turn over a leaf. As we handle the sheet of paper, we're reminded of its fragility.

That reminder becomes a memento mori in "Scraps of Value: The Economics and Aesthetics of Words in Qing (1644-1911) China," where Alex Des Forges turns our attention from the production of books to their disposal. The problem isn't, of course, unique to China: until recently, most reading matter in the West was made from rags and went on to be recycled in turn. The newspaper handed down a chain of households as its contents staled, the letters torn to light a pipe, the folio sold for cutting out patterns or lining pie-plates or wiping shit: in its passage from hand to hand and use to use, old paper corroborates Natalie Davis's description of the book as "not merely a source for ideas ... but a carrier of relationships." In China, however, "societies for cherishing writing" invented an elaborate system to prevent used paper from becoming raw material for new uses. Word-cherishing societies responded to banalization of literacy and its spread to persons outside the elite, including women; but they reacted just as much against a generic democratization that forced scholarly and religious works to share their medium - paper with "almanacs, textbooks, guides to writing examination essays, novels, collections of verse, and even handbills and posters," not to mention clothing tags, hat labels, bank envelopes, teabags, cake wrappers, and umbrellas.

Those societies' ambition to quarantine high art from low materials stands as far as possible from the book-historical enterprise. The discipline's most memorable titles juxtapose the two: thus, Robert Darnton's The Business of Enlightenment and D.F. McKenzie's "Printers of the Mind," for example, pair the human spirit with the manufacture of commodities. In that spirit, Evan Brier's essay in this issue examines the saleability of avant-garde literature between the wars, taking the literary agent as a figure for the economic value of cultural marginality. Indeed, book historians' ambition to reverse center with periphery may help explain why marginalia have been so central to the history of reading. ${ }^{4}$ Our gaze has been redirected to all the spaces that threaten to fall of the edge of the book: margins and endpapers, but also tables of contents, copyright pages, dust jackets. Peter McDonald's essay in this issue more explicitly questions the relation of inside to outside - of the book, but also of literary theory. McDonald's starting-point (as perverse as it's pedantic) is to retranslate a slogan by the most iconic of theorists as a crypto-bibliographic observation. In McDonald's reading, Derrida's aphorism "il n'y a pas de hors-texte" refers not to the opposition between text and context, but rather to the distinction between text and paratext - more literally, between letterpress and tipped-in plates.

As John Nichols shows in "Constructing the Postwar 'Art Novel'," Ezra Pound's anthologies challenged a related distinction between the literary work and its editorial apparatus, making paratexts an object of readerly labor rather than devices to circumvent it. In "Race and the [Para]textual Condition," Beth McCoy identifies paratexts as especially important for African American authors, who lack the self-generating autonomy of the liberal subject. Analyzing the white-authored prefaces of slave narratives, McCoy contrasts "public, textualized" racial 
confrontations with 'hidden, indirect, and paratextualized" ones. One might counter, of course, that paratexts are anything but hidden: prefaces go unread precisely because they lie in plain sight. To read the paratext is to rehabilitate the obvious: at its most polemical, book history can challenge literary critics' reflex to privilege latent meanings over manifest content.

In its disjunction between surface and depth, symptomatic reading can be seen as corollary of a different vocational technique, cryptography. Literary conventions have often been compared to codes; Alice Brittan reverses that metaphor, analyzing the bibliographical cruxes facing cryptographers during World War II. By basing code on texts well-known enough to exist in multiple locations (whether pages or memories), coders ratified a national canon but also made themselves vulnerable to discrepancies among editions. Other critics have remarked on the intertextuality of The English Patient; Brittan calls our attention instead to what might be dubbed its interbibliography, the network linking one book-object to another. If, as Brittan argues, "the war made print both weapon and shield of embattled nations," a more radical materialism might prompt readers to literalize both of those metaphors: pages torn from books were used throughout early modern Europe not only to block bullets (usually by soldiers carrying bibles in their pockets) but to wad them.

In its fascination with the mundane, the material and the social, the realist novel might appear to provide the easiest testing-ground for book history. But where does a genre as individualist as autobiography fit within what Jerome McGann has called the "socialization of texts?" Once answer lies in terminology: where other critics speak of "self-writing," Jody Greene's topic might be termed self-printing. You can, of course, read backward into almost any early modern autobiography a premonition of twentieth-century arguments that agency and interiority depend on language; Greene's crucial departure is to replace "language" with "print." By subordinating the metaphor of the pen to the practices of the press, and textual content to paratextual forms, Greene transforms the autobiographer Francis Kirkman from a forerunner of linguistically constructed subjectivity to a precursor of something more like what Katherine Hayles has recently dubbed "media-specific analysis." Greene's materialist theory of autobiography doesn't simply provide a way out of the idealism that expressive models of self-writing share with poststructuralist theories of subjectivity. The imaginative audacity with which she invests Kirkman also reminds us how far our own discipline's understanding of print culture lags behind the models and metaphors invented by those closer to the ground.

Kirkman is not alone in his self-consciousness about the media through which his words circulate. As Paula McDowell shows, Defoe's Journal of the Plague Year opposes a "backwards" past associated with orality to a new, print-oriented modernity that depends on the collection and reproduction of numbers. Like Greene, McDowell traces back to early modern texts a paradigm that still shapes scholarship today: in this case, the myth that orality precedes literacy rather than existing alongside (and in tension with) it. Defoe acknowledges the fallibility of printed sources like bills of mortality even as he substitutes imaginary physicians for the actual source of those bills, illiterate women who went house-to-house to determine the cause of death. Where the illiterate normally depended on the literate for access to printed news, the plague suddenly made literate authorities dependent on illiterate women's reports of "tokens" on infected bodies. Yet talk spreads the plague, in Defoe's account, as surely as "printed Directions" contain it.

In a third prehistory of media studies, Andrew Piper asks how print shaped modern 
understandings of the literary work. Goethe's late writing (and publishing), he argues, reimagined the printed book in terms of event rather than monument. (The English language incorporates that tension, one might add, by making "publication" refer at once to a process and a product.) The Wanderjahre located the work of literature not in some ideal space, but instead in the material operations of circulation, distribution, and reproduction. Piper uses the reader figured in the Wanderjahre, in short, as an avatar of the reader that the discipline of book history aims to construct today.

Piper's refusal to distinguish theory from practice reminds us that book history's object of study is also its means of transmission. ${ }^{5}$ Because their message coincides with their medium, the same case studies that enable ethnographic defamiliarization can become coded self-portraits. (What academic dutifully flipping through PMLA wouldn't want to imagine himself as a miller reading in defiance of the Inquisition?) In fact, those past practices that appear most exotic are often precisely those that resonate most with twenty-first-century readers. As Matthew Brown shows in "The Thick Style: Steady Sellers, Textual Aesthetics, and Early Modern Devotional Reading," sermons published in colonial New England were multimedia events, pointing outward to manuscript marginalia in printed books and written notetaking on oral performances. Like electronic media, they engaged multiple senses in public and private settings; like digital documents, they sacrificed textual stability for wide dissemination; and like the structure of hypertext, their modular organization encouraged cross-referencing.

Some observers have explained scholars' growing interest in book history by hypothesizing that the rise of digital media has made it harder to take the book for granted. Brown's model of early modern devotional reading, however, relies more heavily on familiarity than on estrangement: the tension that it identifies between linear reading and random-access navigational strategies cuts across the divide between high and low technologies, or between seventeenth-century and twenty-first-century genres. Where McLuhan's generation invested its rhetorical energies in brash generalizations, recent book-historical scholarship has distrusted grand narratives. Brown's argument draws on Peter Stallybrass's plea to subordinate the axis separating print from digital media to that distinguishing codex and DVD (which are searchable) from scroll and film (which impose a single linear sequence upon their users). Yet as Stallybrass and Brown both emphasize, what's at stake is less any contrast between the attributes that inhere in different media than an investigation of the competing strategies that readers have used to move through a single medium. The codex itself presents readers with a constant choice between passive and active navigational styles, whose material corollaries are the table of contents and the index, the running head and the concordance, the abridgment and the anthology, the skim and the skip.

If book historians have become especially interested in the second of those options, it may be less because the personal computer has accustomed us to discontinuity than because we've come to distrust the place of sequence within our own work: to disclaim a history that runs from intensive to extensive reading, or from manuscript to print, or from orality to literacy. McDowell's article in this issue exemplifies a new tendency to imagine the relation between speech and writing in terms of competition rather than succession: some historians now trace printers' distribution mechanisms back to manuscript book dealers, while others show how persistently the page layout of early printed books mimicked that of manuscripts, rather as our word-processing interfaces now 
depend on verbal metaphors (the "desktop") and visual allusions (the paper-clipped attachment). Conversely, recent studies have shown how stubbornly manuscript circulation survived the emergence of print: well into the eighteenth century, handwriting remained the preferred form for some kinds of poetry and some forms of political reporting. Scholars are now less likely to think of manuscript being displaced by print than to conceive of both as competitors carrying out complementary roles (and freighted with different connotations) at any given time and place.

Yet a resistance to grand narrative doesn't necessarily reduce book history to a jumble of disconnected particulars. In attacking the conventional subordination of image to word, paratext to text, extrinsic to intrinsic criticism, McDonald challenges the standoff between a leather-jacketed literary theory and a cardigan-clad historical empiricism. To pit the soaring (or flighty) ambitions of theory against the grounded (or plodding) procedures of bibliography is to understate the stakes of both. Each questions the terms that underlie our critical practice: what is an author, a reader, a work, a text? Even the dowdiest subset of book historians - textual editors - share many of their working hypotheses with the very theorists who dismissed them as a service industry. Poststructuralism reinvented the articles of skepticism which bibliographers had long taken for granted: the instability of the text, the productivity of misreading, the slipperiness of authorial intention. The word "Idea" in our title represents a bid to situate the study of material culture as a player in theoretical debates rather than a bolthole from which to wait them out. If PMLA members were to follow Hardy's injunction, we might end up telling a different story about our own discipline. 